\title{
PLASTIC VISION FOR TEACHING METAL WORK
}

\author{
Salwa Mahmoud HANAFI*
}

Metal Works Department, Faculty of Specific Education, Cairo University, Egypt

\begin{abstract}
The contemporary art education programs are specially designed to cope with the rapid educational and technological changes in the developed societies. Therefore, they have been able to cope with this educational change by providing them with the skills and techniques that will help to perform more sophisticated artistic works. Metal works are one of the applied fields of art education, which aims to contribute with other fields of art education in the preparation of the intellectual student who is creative behavior, and this necessarily requires the continuation of training and self-discovery methods of formation necessary for the production of art to have a balance of experience and knowledge and aesthetic vision that Aims to increase the level of intellectual and plastic performance as well as prepare it to face the labor market.

Keywords

Plastic, Vision, Teaching, Metal Work.
\end{abstract}

\section{Introduction}

Crafts of different types and shapes belong to the field of metal works in terms of form and function. The art of jewelry has the flexibility to achieve communication with the world and development in the form of products and works of art that are highly responsive to the challenges posed by technology problems and innovations. This vital field, which is directly related to the functional purpose and life of man and the value of use in addition to the aesthetic values and quality of technology, which has achieved the jewelers place in the community as an art of a special nature in the breadth of its spread, brings together a whole, whatever the culture of society and the environment from the countryside or attended.

The current research examines the adaptation of methods and methods of the formation of manual metals in proportion to the educational field and develops the intellectual and imaginative side, and formulation in the form of costume and taking into account the functional aspect of it, where the play function of artistic work plays an important role cannot be left to chance, but according to the awareness and experience gained Of the experimentation processes are affected by the nature of the material used and the techniques used, which affects in one way or another the type and shape of the tool used in the formation, so there are several factors affecting mainly on the most important and the most important of the methods and methods of performance, which includes materials, tools and techniques, Which combine to produce a work of art holds many and many of the values of plastic, Which plays an important role in the achievement of the greatest possible aesthetic values to be achieved, and based on

\footnotetext{
* Corresponding author: fose@cu.edu.eg
} 
the formal and formal properties of materials, which suggest its visual properties and visual possibilities for many innovations

Based on the above, the precise selection of tools and methods of formation suitable for the properties of materials used can effectively contribute to the transformation of mental ideas in each artist's imagination into tangible material reality. The more information the artist uses about the medium that he uses, the more materials, and increased its executive results, and then contributed to the increase and revitalization of thought and visual imagination

Therefore, the study in the current study to determine the raw material used in the red copper and its alloys of copper as a mineral ore used in the current educational field, which are available in different shapes and sizes in the educational environment, the most appropriate tools that can be used to adapt them manually, Between the fold and the fold to achieve the visions of a new plastic in the construction of jewelry, especially if invested in light of some of the trends of contemporary art

Hence, the aim of this study was to attempt to uncover the plastic possibilities of combining the formation of the clay and the folding, whether by relying on the practices and experiences that are the nucleus and the beginning of the stage of the finished works, or become the same part on which the parts are built, It is used during the initial imaginations of the contact group and the plastic levels that are suitable for the idea and subject matter, or by employing these different experiences by adjoining, spacing and overlap and trying to employ them in the plastic structure of the work.

\section{Research Problem}

The research problem solves the following question:

* Is it possible to achieve the visions of the formation of a combination of bending and folding as an input to teach the metal works? How is this achieved?

\section{Research Objectives}

The introduction of new experimental entrances that combine the formation of soft and foldable valid for teaching metal works and to identify the extent to which it can be used and the addition of the possibilities of formality and technical dimensions of the production of metal jewelry innovative characterized by the diversity and rich surfaces with many values and aesthetic values.

\section{Research Methodology}

The research follows the experimental method to suit the objectives of the research and verify its hypotheses. 


\section{Results}

- Discovering new experimental approaches that are compatible with contemporary intellectual, educational and artistic developments.

- The importance of experimentation based on scientific foundations to reach aesthetic dimensions and innovative performance.

- Provide a wider scope for the exploitation of chips, sheets and mineral waste.

- Access to surface and tactile surface treatments by combining the soft and soft in the formation.

- The possibility of combining in the formation between the fold and fold with different bodies, whether by following the stages that have been presented or guided and access to other ideas and solutions.

\section{References}

- Nermin HAMDY, A PROPOSED PROGRAM TO TEACH CHILDREN FRENCH LANGUAGE BY PLAYING THE PIANO, International Journal of Education and Learning Research, Vol. 1, No. 1, 2018, pp. 1-9.

- Salwa Hassan Mohamed Mahmoud PASHA, ADVANTAGES OF BREATHING EXERCISES ON PIANO PERFORMANCE FOR BEGINNERS, International Journal of Education and Learning Research, Vol. 1, No. 1, 2018, pp. 10-17.

- Ola Ali Alwan OMAR, ATTITUDES OF STUDENTS OF CLOTHING AND TEXTILE MAJOR TOWARDS WORK IN THE FIELD OF HANDICRAFTS (EMBROIDERY), International Journal of Education and Learning Research, Vol. 1, No. 1, 2018, pp. 18-26.

Received: August 22, 2018

Accepted: October 18, 2018 